\title{
Improved Isolation of Microbiologically Produced (2R,3S)-Isocitric Acid by Adsorption on Activated Carbon and Recovery with Methanol
}

Andreas Aurich ${ }^{*}, \dagger$ Jörg Hofmann ${ }^{\ddagger}$ Robert Oltrogge, ${ }^{\ddagger}$ Mike Wecks, ${ }^{\ddagger}$ Roger Gläser ${ }^{\ddagger}$ Laura Blömer, Stephan Mauersberger, ${ }^{\xi}$ Roland A. Müller, ${ }^{\dagger}$ Dieter Sicker, ${ }^{\|}$and Athanassios Giannis*, ${ }^{*}{ }_{\odot}$

${ }^{\dagger}$ Helmholtz Centre for Environmental Research GmbH - UFZ, Permoserstraße 15, 04318 Leipzig, Germany

${ }^{\ddagger}$ Institute of Nonclassical Chemistry e.V., Permoserstraße 15, 04318 Leipzig, Germany

${ }^{\S}$ Institute of Microbiology, Technical University of Dresden, Zellescher Weg 20b, 01062 Dresden, Germany

"Institute of Organic Chemistry, University of Leipzig, Johannisallee 29, 04103 Leipzig, Germany

Supporting Information

ABSTRACT: A new, efficient method for the isolation of $(2 R, 3 S)$-isocitric acid (ICA) from its fermentation solution was developed. It is noteworthy that this method is based on selective adsorption directly from the fermentation solution on activated carbon, followed by the release of both ICA and citric acid by means of elution with methanol and their final separation by known methods. Thereby, several disadvantages were overcome: Electrodialysis is no longer necessary to remove cations such as $\mathrm{Na}^{+}$from the fermentation solution. Also, several hitherto accompanying dyestuffs were not observed with this method. Furthermore, removal of water by distillation is expendable. Eventually, the new crude product is of a quality that also avoids the use of a tedious slide vane rotary vacuum pump distillation of the trimethyl esters of both acids, which hitherto was the basis for the separation of ICA. In summary, the new method distinctly spares energy as well as time.

KEYWORDS: Activated carbon (AC), isocitric acid, yeast bioprocess, esterification, plant oil, Yarrowia lipolytica

\section{INTRODUCTION}

A few years ago, we introduced $(2 R, 3 S)$-isocitric acid (ICA (1); Figure 1), a substance that was only of analytical interest at that time, as a new member of the chiral pool. ${ }^{1}$ In the meantime, this member of the citric acid (CA) cycle has now become available for synthesis or other applications in kilogram amounts from the fermentation solution of Yarrowia lipolytica yeast strains and renewable plant oil (e.g., sunflower or rapeseed oil) as a substrate, although it cannot be purchased commercially yet.

ICA has hitherto been used for the multigram synthesis of several chiral derivatives, as shown in Figure 1.

Firmly convinced that this compound has prospects, we have worked at improving the access to ICA in several directions. This effort was also supported by several publications related to ICA

(a) Several authors reported on the role of isocitrate in erythroid development. ${ }^{2}$ It has been found that the formation of erythrocytes is regulated by iron-sulfur enzymes (aconitases) that catalyze the isomerization of citrate to isocitrate. Iron deficiency leads to reduced aconitase activity, whereas exogenous isocitrate abrogates the erythroid iron restriction response in vitro and reverses anemia progression in iron-deprived mice.

(b) Rånby et al. reported that isocitrate can be used to buffer $\mathrm{Ca}^{2+}$ activity at physiological concentrations and therefore can serve as an anticoagulant. ${ }^{3}$

(c) Recently, Moore et al. described a multigram synthesis of furofuranol derivative 10 starting from ICA. ${ }^{4}$ This bis- tetrahydrofuran alcohol is an important building block for the synthesis of several clinically useful HIV protease inhibitors like darunavir, brecanavir, GS-9005, and SPI$256^{5}$

All of these applications underline the extraordinary role of isocitric acid as a promising chiral pool educt or for direct usage.

\section{RESULTS AND DISCUSSION}

Generation of ICA from Natural Materials. The isolation and enrichment of ICA from natural materials, e.g., leaves of Crassula plants, is tedious, complicated, and associated with low product yields. $^{6-8}$ The biosynthesis of ICA by the nonconventional yeast $Y$. lipolytica from hydrophobic substrates, e.g., fats, oils, fatty acids, $n$-alkanes, and ethanol, is more efficient. ${ }^{9-11}$ Unfortunately, wild-type Y. lipolytica strains accumulate $>90 \mathrm{~g}$ $\mathrm{L}^{-1}$ only in mixtures of ICA and CA, wherein the ICA/CA molar ratio ranged from $1.1: 1$ to $1.4: 1.1,9,12,14$ Strategies to increase the selectivity of ICA or CA formation include classical strain mutagenesis ${ }^{10}$ or the use of isocitrate lyase inhibitors such as itaconate ${ }^{13}$ on the one hand and strain improvement by genetic modifications on the other hand. ${ }^{14-16} \mathrm{~A}$ particular target is the overexpression of the aconitase encoding ACO1 gene in $Y$. lipolytica, a key enzyme of the ICA formation pathway. The recombinant strain Y. lipolytica H222-S4(p67ACO1) T1 with 8-10 copies of the ACO1 gene increased

Received: March 11, 2017

Published: May 17, 2017 


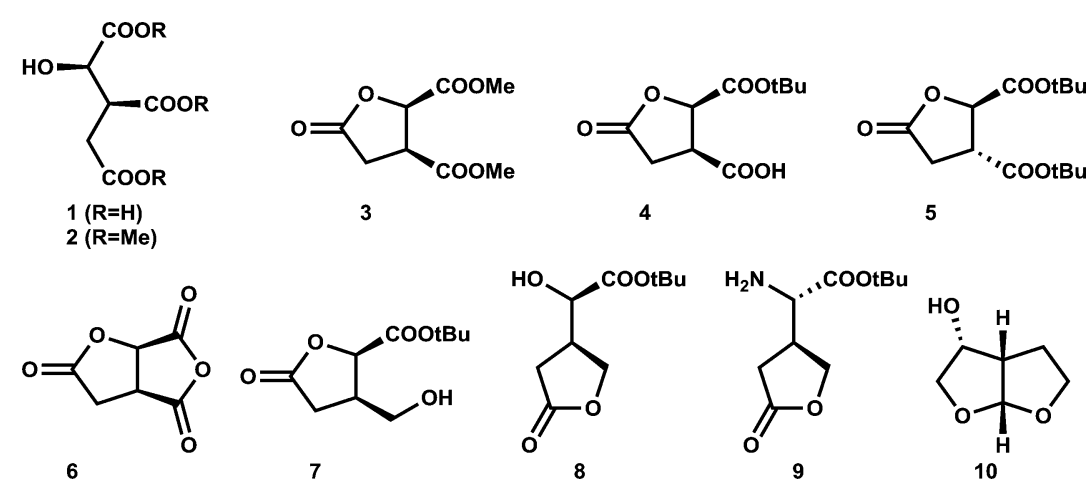

Figure 1. (2R,3S)-Isocitric acid (1) and functionalized derivatives 2-10 obtained from it.

the ICA/CA ratio to $2.4: 1$ in sunflower oil in comparison to the wild-type strains (ICA/CA ratio from $0.54: 1$ to $1: 1$, i.e., $35-$ 49\% ICA with strains $\mathrm{H} 222$ or $\mathrm{H} 222-\mathrm{S} 4){ }^{14}$

The ACO1 multicopy strain $Y$. lipolytica H222-S4(p67ACO1) T1 was used in this work, wherein applying the bioprocess under optimized bioreactor conditions led to a further increase in the selectivity of ICA production to $75-80 \%$ (details will be published elsewhere).

After $144 \mathrm{~h}$ of cultivation time, $68.4 \mathrm{~g} \mathrm{~L}^{-1}$ ICA was determined in the cultivation broth. The molar ratio of ICA/ CA was distinctly enhanced from nearly 1:1 (wild-type strains) to 3.1:1. Detailed experimental data on the bioprocess is given in the Supporting Information.

Isolation of ICA from Natural Materials. The isolation of ICA was addressed as a process that offers both challenges and opportunities for simplification. The main weak points in the current methods ${ }^{1}$ are (1) the need for electrodialysis, a step that was necessary to remove $\mathrm{Na}^{+}$ions from the fermentation solution in which they came by stabilization of the fermentation $\mathrm{pH}$ with $\mathrm{NaOH},(2)$ the coloration of the fermentation solution that was passing through the electrodialysis, and (3) the considerable amount of water that had to be removed by distillation in vacuo after electrodialysis prior to the first step of separating ICA from CA, i.e., their esterification into separable trimethylesters (hitherto, this step additionally included an ambitious distillation in vacuo).

Enrichment of Carboxylic Acids from Fermentation Solutions by Adsorption. Adsorption is a very effective technology for the separation of low-concentration materials from complex mixtures in a fluid phase. The affinity, capacity, and selectivity of the adsorbent and the relationship between the adsorptive state and water determine the separation process.

The recovery of carboxylic acids by solid materials was investigated with the goal of concentrating the acids. The use of anionic exchange resins and nonionic materials was applied to aqueous carboxylate solutions obtained after the fermentation process, for instance, sodium salts from lactic, succinic, and CAs. A usual way to recover the carboxylate is to capture the organic anions at the surface of a strong anionic exchange resin. The purity of the recovered acids depends on the concentration of the organic acids and all other anions in the fluid phase and the selectivity of the ion exchange material. The acids can be removed from the surface by treatment with $\mathrm{NaOH}$ solution, yielding a highly concentrated aqueous solution. Caused by the presence of inorganic acids in the fermentation solution, the product contains their salts too. To obtain pure acids, a multistep treatment by membrane separation and dialysis steps is necessary. ${ }^{17}$

The adsorption of carboxylic acids on mineral materials such as alumina or hematite is described at high $\mathrm{pH}$ values. However, the sorption capacities were too low for this to be considered as a recovery method. ${ }^{18,19}$ Hydrophobic high-silica sorbents were explored. Desorption with pressurized water at higher temperatures was not successful. The use of water-soluble organic solvents under ambient conditions was not effective. The strong adsorption of organic solvents necessitates a regeneration step at high temperature. ${ }^{20}$

In this article, we report solutions for all of the problems mentioned above; these arise from using an adsorption process for the selective removal of both tricarboxylic acids directly from the fermentation solution.

Enrichment and Isolation of ICA/CA. The development of the new adsorption process for the enrichment and isolation of ICA was performed in two steps. In the first step, the influence of the $\mathrm{pH}$ value on the adsorption process was investigated in detail. In the second step, various desorption procedures were studied and evaluated to select the optimum method.

For example, the adsorption of reactive dyes containing three or more sulfonic acid groups and of other ionic components on activated carbon is influenced by the type of activated carbon and the parameters of the water phase, e.g., $\mathrm{pH}$ value or ionic strength. ${ }^{21}$ Because ICA and CA are tricarboxylic acids with an alcohol group, the effect of solution $\mathrm{pH}$ on the adsorption of ICA/CA was investigated primarily. In Figure 2, the adsorption isotherms for an ICA/CA mixture (78:22) at different $\mathrm{pH}$ values are shown. The significant influence of the $\mathrm{pH}$ value of the water phase on the adsorption behavior can be explained by the surface functional groups and the $\mathrm{pH}_{\mathrm{pzc}}$ of the activated carbon and the dissociation equilibrium of ICA/CA given by the $\mathrm{pK}$ a values (Table 1 ). The $\mathrm{pH}_{\mathrm{pzc}}$ of the activated carbon describes the acidity/basicity and the net surface charge in solution. The surface groups of the activated carbon are carboxy, hydroxy, and phenolic groups. ${ }^{22}$ The basic functional groups include oxygen containing species and $\pi$-electron systems of carbon basal planes. The density of surface functional groups depends on the preparation technology and the precursor. $^{23}$ The combined influence of all functional groups determines $\mathrm{pH}_{\mathrm{pzc}}$ the $\mathrm{pH}$ value at which the net surface charge on the carbon is zero. At $\mathrm{pH}<\mathrm{pH}_{\mathrm{pzc}}$ the carbon surface has a net positive charge, whereas at $\mathrm{pH}>\mathrm{pH}_{\mathrm{pzo}}$ the surface has a net negative charge. ${ }^{24}$

In Figure 3, the influence of the $\mathrm{pH}$ value of the water phase on the equilibrium loading of $\mathrm{CA}$ on activated carbon and the 


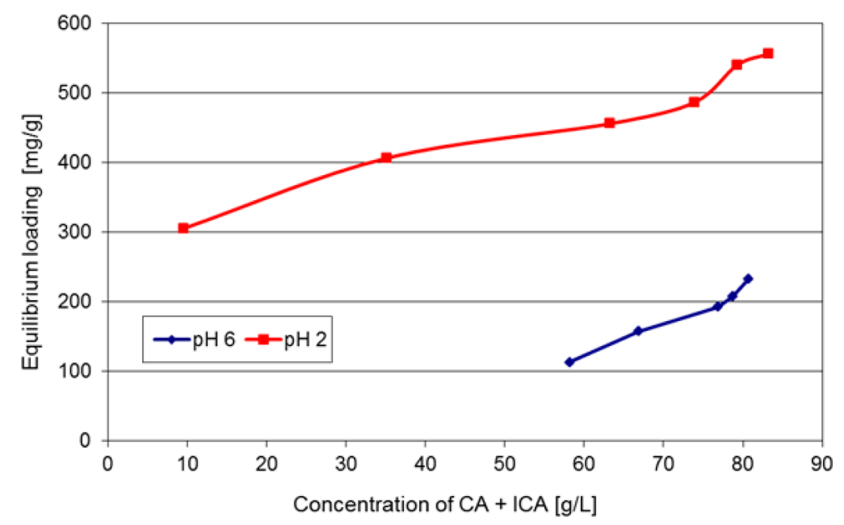

Figure 2. Adsorption isotherms of ICA/CA (78:22) at different $\mathrm{pH}$ values. $\mathrm{pH} 6$, untreated fermentation solution; $\mathrm{pH} 2$, prepared by addition of sulfuric acid to the fermentation solution. Conditions: different amounts of activated carbon, $86 \mathrm{~g} \mathrm{~L}^{-1}$ ICA/CA mixture, 25 ${ }^{\circ} \mathrm{C}$.

Table 1. $\mathrm{pK}_{\mathrm{a}}$ Values of ICA and $\mathrm{CA}^{25,26}$

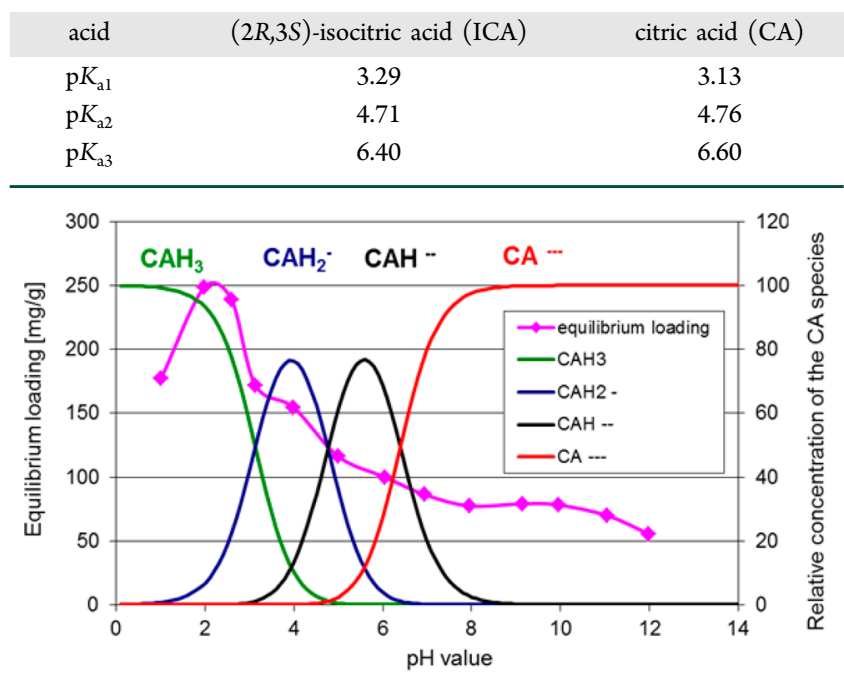

Figure 3. Influence of $\mathrm{pH}$ on the equilibrium loading of $\mathrm{CA}$ on activated carbon and on the dissociation of CA.

dissociation behavior of CA are shown. Because of their similar $\mathrm{p} K_{\mathrm{a}}$ values, the functions for CA and ICA are almost the same. The highest loading was observed at $\mathrm{pH}$ values in the range of 1.5-2.5. In this $\mathrm{pH}$ region, the surface loading of the activated carbon is positive and ICA is in its neutral or single negatively charged form. At $\mathrm{pH}<1$, the $\mathrm{OH}$ group of $\mathrm{CA}$ is protonated, resulting in a positive charge. The charged CA and the surface of the activated carbon repell each other. In alkaline medium, the surface of the activated carbon and the deprotonated CA had the same negative charge and repell each other too.

Independent tests on the adsorption of sulfuric and hydrochloric acids show the adsorption of inorganic acids in traces only. The high selectivity of the activated carbon used in the tests allows the enrichment of a mixture of ICA/CA in the absence of other components. The product is nearly free of inorganic acids. This point is the advantage of activated carbon over ion-exchange resin, which accumulates all acids at its surface.

Tests of the Desorption of ICA/CA. To remove the ICA/ CA from the surface of the activated carbon, two approaches can be followed: changing the $\mathrm{pH}$ value to be in the alkaline range or using organic solvents. Both ways are feasible. In the first step, the loaded activated carbon needs to be washed with water to remove the components of the fermentation solution.

The desorption of ICA/CA can be performed using a diluted $\mathrm{NaOH}$ solution at $\mathrm{pH} \geq 12$. This can be done because the adsorption equilibrium at high $\mathrm{pH}$ values is shifted to the water phase. Using this effect, more than $99 \%$ of ICA/CA can be removed. After removal of the water by distillation, the sodium salt of the organic acids can be isolated. For the further processing (esterification and fractional crystallization), the salts cannot be used. An additional preparation step, e.g., electrodialysis, is necessary.

To avoid the formation of sodium salt, an organic solvent can be used to remove ICA/CA from the activated carbon. By drying the loaded and washed activated carbon, large amounts of the water can be removed. Desorption with organic solvents possessing low boiling points offers the possibility of isolating the ICA/CA mixture in the form of the pure acids. To select the solvent, the physical and chemical properties of the solvent and the conditions of the previous and following preparation steps were considered. In the esterification, methanol is used as the solvent. After drying, the activated carbon contains traces of water, which is miscible with alcohols and acetone. Desorption of ICA/CA can be achieved by polar organic solvents like dichloromethane, acetone, ethanol, and methanol in high yields. The recovery rate of ICA/CA is summarized in Table 2. In due consideration of the points described above, methanol was selected for the desorption of the organic acids.

Table 2. Recovery Rate of ICA/CA in the Extraction of Activated Carbon with Various Organic Solvents ${ }^{a}$

$\begin{array}{lc}\text { organic solvent } & \text { recovery rate (\%) } \\ \text { methanol } & 90 \\ \text { ethanol } & 87 \\ \text { 2-propanol } & 69 \\ \text { 2-butanol } & 68 \\ \text { acetone } & 72\end{array}$

${ }^{a}$ Conditions: $2.4 \mathrm{~g}$ of activated carbon, loading: $80-100 \mathrm{mg} \mathrm{g}^{-1}$, extraction four times with organic solvent, $25^{\circ} \mathrm{C}$.

Fixed-Bed Adsorption Studies: Breakthrough Tests. On the basis of the described results, adsorption of the ICA/ $\mathrm{CA}$ mixture was carried out after reducing the $\mathrm{pH}$ value of the original fermentation solution from 6 to 2 by the addition of sulfuric acid. A fixed-bed adsorber with an inner diameter of 30 $\mathrm{mm}$ and a height of $170 \mathrm{~mm}$ was filled with activated carbon (Blücher $\mathrm{GmbH}$ ) and washed with distilled water. The acid solution with a $91 \mathrm{~g} \mathrm{~L}^{-1} \mathrm{CA}$ and ICA mixture was pumped through the adsorber. Figure 4 represents the schematic diagram of the fixed-bed adsorption/desorption (eluation) system. The breakthrough can be detected directly by a $\mathrm{pH}$ detector (Figure 5). A loading of about $400 \mathrm{mg} \mathrm{g}^{-1}$ was calculated from the concentration of ICA/CA in the water phase in the inlet and outlet streams and the mass of activated carbon used in the fixed bed. The calculated loading corresponds to the data determined by the adsorption isotherm procedure.

Fixed-Bed Desorption Studies: Recovery of ICA/CA. The fixed bed loaded with an ICA/CA mixture was treated with methanol to remove the organic acids. The test was carried out with a fixed bed containing $50 \mathrm{~g}$ of activated carbon loaded with $20 \mathrm{~g}$ of the ICA/CA mixture. A methanol flow of $1 \mathrm{~mL} \mathrm{~min}^{-1}$ 


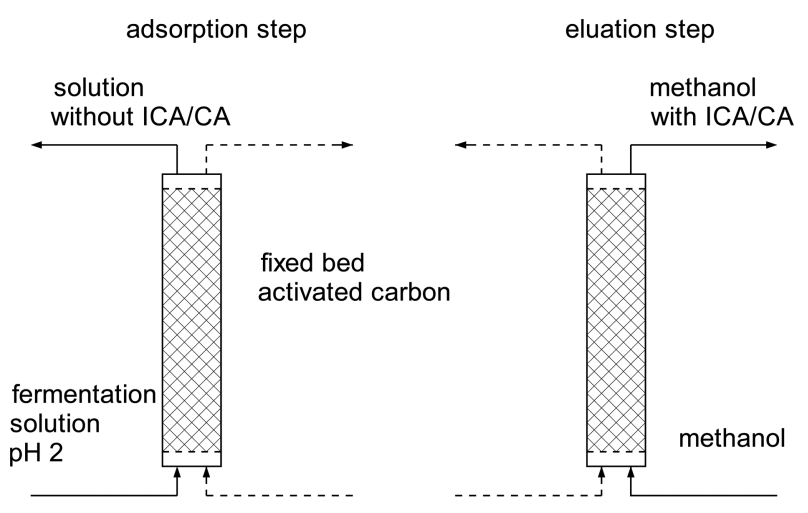

Figure 4. Schematic flow diagram of the fixed-bed system used in the tests.

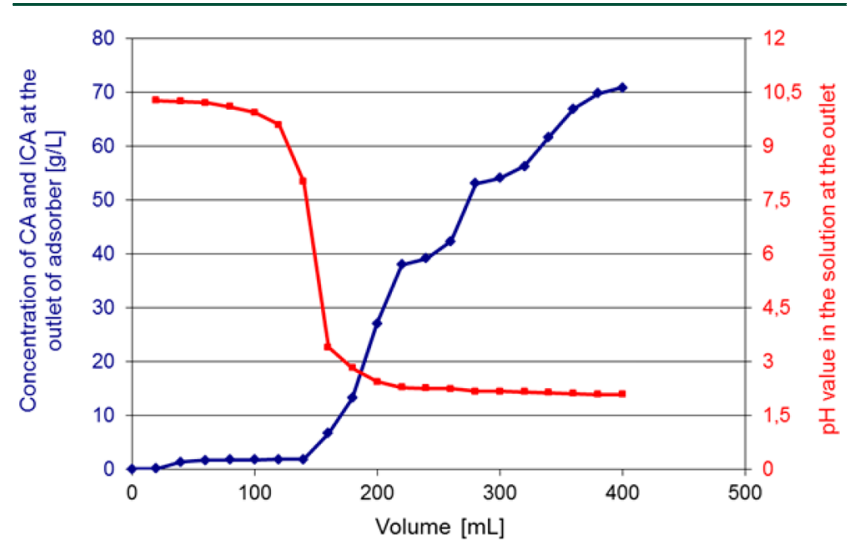

Figure 5. Breakthrough curve of ICA/CA with a fixed-bed activated carbon adsorber. Conditions: $50 \mathrm{~g}$ of activated carbon, loading: 400

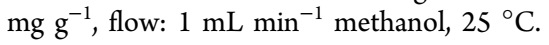

was pumped through the air-dried activated carbon bed. At the outlet of the fixed bed, $10 \mathrm{~mL}$ fractions of methanol were taken and analyzed (Figure 6). In the first $40 \mathrm{~mL}$ of methanol, water and traces of sulfuric acid were found. In the next fractions (from 50 to $150 \mathrm{~mL}$ ), more than $95 \%$ of the organic acids was eluted. These fractions can be collected and directly used in the esterification because they are free from water and sulfuric acid.

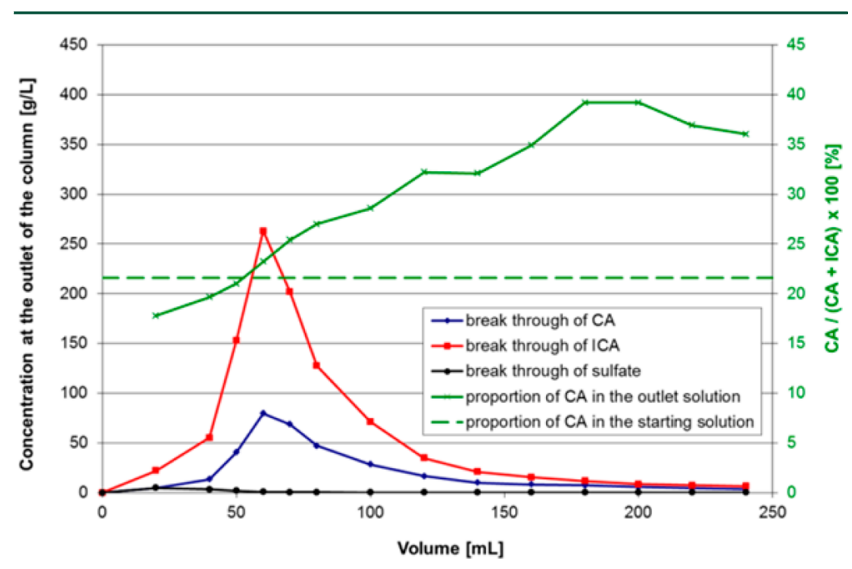

Figure 6. Concentration of the acids as a function of the pumped volume at the outlet of the fixed bed during the recovery of ICA/CA. Conditions: $50 \mathrm{~g}$ of activated carbon loaded with $20 \mathrm{~g}$ of ICA/CA, methanol flow: $1 \mathrm{~mL} \min ^{-1}, 25^{\circ} \mathrm{C}$.
Alternatively, by evaporation of the solvent, a mixture of ICA/ CA can be obtained.

Thus, by using the described fixed-bed adsorption/ desorption with activated carbon, the aqueous fermentation solution after crossflow microfiltration $\left(73 \mathrm{~g} \mathrm{~L}^{-1} \mathrm{ICA}+\mathrm{CA}\right.$, $76.7 \%$ ICA) was easily transferred into a methanolic ICA/CA solution containing these two acids in an almost similar ratio (120 $\mathrm{g} \mathrm{L}^{-1} \mathrm{ICA}+\mathrm{CA}, 73.2 \%$ ICA, free from water and sulfuric acid) ready for further use.

For isolation of ICA by esterification and fractional crystallization, our method as reported was adapted and is described in the Supporting Information. ${ }^{1}$

\section{CONCLUSIONS}

By the new procedure described herein, ICA can be isolated in good yield and high purity (Figure 7). In contrast to the

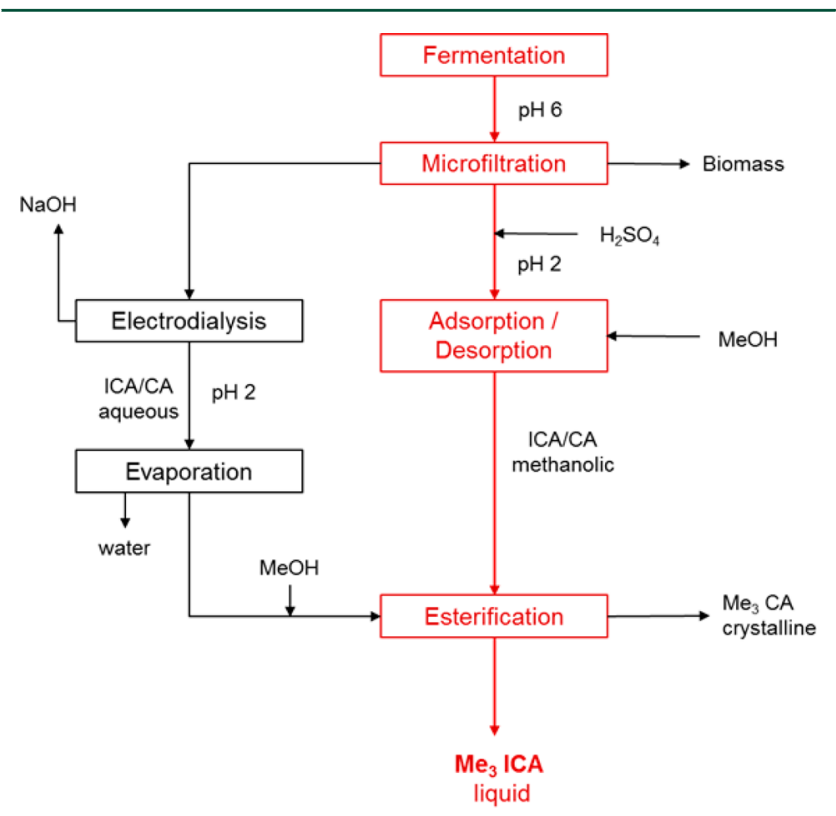

Figure 7. Flowchart of proposed ICA isolation by adsorption/ desorption steps (red boxes) and steps from the previous method that are avoided $^{1}$ (black boxes).

method described previously, ${ }^{1}$ ICA can now be obtained in a simplified way by adsorption on activated carbon and desorption with methanol. Separation of ICA from the accompanying $\mathrm{CA}$ is then possible by esterification to form both trimethylesters, from which the CA trimethylester is removed by crystallization, with the liquid ICA trimethyl ester remaining in a highly enriched form, ${ }^{1}$ allowing the synthesis of $(2 R, 3 S)$-isocitric acid lactone-2,3-dicarboxylic acid dimethylester $(3)$ or the corresponding $(2 R, 3 S)$-isocitric acid lactone-2,3dicarboxylic acid as pure ICA building blocks from the chiral pool.

The important advantage of adsorption with activated carbon is the high selectivity. Only organic acids are accumulated at the surface of the adsorbent. Inorganic acids and salts remain in the fermentation solution. In contrast, ion exchange resins have no selectivity with respect to acids. The recovery of ICA, CA, and other organic acids can be accomplished by extraction of the activated carbon with methanol or other organic solvents.

Several disadvantages have now been overcome: Electrodialysis is no longer necessary to remove cations such as $\mathrm{Na}^{+}$ from the fermentation solution. Several hitherto accompanying 
yellowish compounds were not observed using this method. A very extensive and tedious removal of water by distillation is expendable. Therefore, the new crude product is of a quality that also avoids the use of a tedious slide vane rotary vacuum pump distillation of the trimethyl esters of both acids, which hitherto was the basis of the separation of ICA. In summary, the new method distinctly spares working time as well as energy.

\section{ASSOCIATED CONTENT}

\section{S Supporting Information}

The Supporting Information is available free of charge on the ACS Publications website at DOI: 10.1021/acs.oprd.7b00090.

Materials and methods; results of the ICA production process; isolation of ICA and CA by adsorption on activated carbon and desorption by methanol treatment; method for working up a mixture of ICA and CA in methanolic solution by esterification (PDF)

\section{AUTHOR INFORMATION}

\section{Corresponding Authors}

*E-mail: andreas.aurich@ufz.de (A.A.).

*E-mail: giannis@uni-leipzig.de (A.G.).

\section{ORCID}

Athanassios Giannis: 0000-0003-2203-0959

Notes

The authors declare no competing financial interest.

\section{ACKNOWLEDGMENTS}

This work was supported by the Saxon State Ministry of the Environment and Agriculture (SMUL), Saxony, Germany (grant nos. 33-8506.42/58/8-2009/16241 and 33-8506.42/ 39/3-2009/15317) and the Federal Ministry for Economic Affairs and Energy (BWMi), Germany (grant INNO-KOM-Ost No. MF130003). The technical assistance of Karin Richter and Renate Herold is gratefully acknowledged.

\section{REFERENCES}

(1) Heretsch, P.; Thomas, F.; Aurich, A.; Krautscheid, H.; Sicker, D.; Giannis, A. Angew. Chem., Int. Ed. 2008, 47, 1958-1960.

(2) (a) Bullock, G. C.; Delehanty, L. L.; Talbot, A. L.; Gonias, S. L.; Tong, W.-H.; Rouault, T. A.; Dewar, B.; Macdonald, J. M.; Chruma, J. J.; Goldfarb, A. N. Blood 2010, 116, 97-108. (b) Talbot, A.-L.; Bullock, G. C.; Delehanty, L. L.; Sattler, M.; Zhao, Z. J.; Goldfarb, A. N. PLoS One 2011, 6 (8), e23850. (c) Richardson, C. L.; Delehanty, L. L.; Bullock, G. C.; Rival, C. M.; Tung, K. S.; Kimpel, D. L.; Gardenghi, S.; Rivella, S.; Goldfarb, A. N. J. Clin. Invest. 2013, 123, 3614-3623. (d) Kim, A.; Fung, E.; Parikh, S. G.; Gabayan, V.; Nemeth, E.; Ganz, T. Blood Cells, Mol., Dis. 2016, 56, 31-36.

(3) Rånby, M.; Gojceta, T.; Gustafsson, K.; Hansson, K. M.; Lindahl, T. L. Clin. Chem. 1999, 45 (8), 1176-1180.

(4) Moore, G. L.; Stringham, R. W.; Teager, D. S.; Yue, T.-Y. Org. Process Res. Dev. 2017, 21, 98-106.

(5) Khmelnitsky, Y. L.; Michels, P. C.; Cotterill, I. C.; Eissenstat, M.; Sunku, V.; Veeramaneni, V. R.; Cittineni, H.; Kotha, G. R.; Talasani, S. R.; Ramanathan, K. K.; Chitineni, V. K.; Venepalli, B. R. Org. Process Res. Dev. 2011, 15, 279-283.

(6) Pucher, G. W.; Abrahams, M. D.; Vickery, H. B. J. Biol. Chem. 1948, 172, 579-588.

(7) Soderstrom, T. R. Am. J. Bot. 1962, 49, 850-855.

(8) Vickery, H. B. Methods Enzymol. 1969, 13, 601-609.

(9) Aurich, A.; Specht, R.; Müller, R. A.; Stottmeister, U.; Yovkova, V.; Otto, C.; Holz, M.; Barth, G.; Heretsch, P.; Thomas, F. A.; Sicker, S.; Giannis, A. Subcell. Biochem. 2012, 64, 391-423.
(10) Finogenova, T. V.; Shishkanova, N. V.; Ermakova, I. T.; Kataeva, I. A. Appl. Microbiol. Biotechnol. 1986, 23, 378-383.

(11) Finogenova, T. V.; Shishkanova, N. V.; Fausek, E. A.; Eremina, S. S. Appl. Microbiol. Biotechnol. 1991, 36, 231-235.

(12) Kamzolova, S. V.; Finogenova, T. V.; Morgunov, I. G. Food Technol. Biotechnol. 2008, 46, 51-59.

(13) Kamzolova, S. V.; Dedyukhina, E. G.; Samoilenko, V. A.; Lunina, J. N.; Puntus, I. F.; Allayarov, R. L.; Chiglintseva, M. N.; Mironov, A. A.; Morgunov, I. G. Appl. Microbiol. Biotechnol. 2013, 97, 9133-44.

(14) Holz, M.; Förster, A.; Mauersberger, S.; Barth, G. Appl. Microbiol. Biotechnol. 2009, 81, 1087-1096.

(15) Förster, A.; Aurich, A.; Mauersberger, S.; Barth, G. Appl. Microbiol. Biotechnol. 2007, 75, 1409-1417.

(16) Förster, A.; Jacobs, K.; Juretzek, T.; Mauersberger, S.; Barth, G. Appl. Microbiol. Biotechnol. 2007, 77, 861-869.

(17) López-Garzón, C. S.; Straathof, A. J. J. Biotechnol. Adv. 2014, 32, 873-904.

(18) Gulicovski, J. J.; Čerović, L. S.; Milonjić, S. K.; Popović, I. G. J. Serb. Chem. Soc. 2008, 73, 825-834.

(19) Hwang, Y. S.; Lenhart, J. J. Langmuir 2008, 24, 13934-13943.

(20) Efe, C.; Pieterse, M.; Gascon, J.; Kapteijn, F.; van der Wielen, L. A. M.; Straathof, A. J. J. Ind. Eng. Chem. Res. 2010, 49, 3794-3801.

(21) Al-Degs, Y. S.; El-Barghouthi, M. I.; El-Sheikh, A. H.; Walker, G. M. Dyes Pigm. 2008, 77, 16-23.

(22) Chun, Y.; Sheng, G.; Chiou, C.; Xing, B. Environ. Sci. Technol. 2004, 38, 4649-4655.

(23) Mattson, J.; Mark, H. Activated Carbon: Surface Chemistry and Adsorption from Solution; Marcel Dekker, Inc.: New York, 1971.

(24) Al-Degs, Y. S.; Khraisheh, M.; Allen, S.; Ahmad, M. Water Res. 2000, 34, 927-935.

(25) Beyer, C. Quantitative Anorganische Analyse: Ein Begleiter für Theorie und Praxis; Gerdes, E., Ed.; Springer Science \& Business: Berlin, 1996; p 96.

(26) Poirier, J. C. Annu. Rev. Phys. Chem. 1959, 10, 247-253.

\section{NOTE ADDED AFTER ASAP PUBLICATION}

This paper was published ASAP on May 24, 2017. The Supporting Information and references 2, 15, and 16 have been corrected. The corrected version was reposted on June 6, 2017. 